\section{References}

Kessel. N. (1984) Communication between GPs and hospital doctors: a hospital consultant's view. In Doctor to Doctor: Writing and talking about patients (eds J. Walton \& G. McLachlan), pp. 14-26. London: Provincial Hospitals Trust.

KING. M. \& PULLEN. I. (1994) Communication between general practitioners and psychiatrists. In Psychiatry and General Practice Today (eds I. Pullen, G. Wilkinson. A. Wright, et al). pp. 251-264. London: The Royal College of Psychiatrists \& The Royal College of General Practitioners.

Midgley, S., BuRns, T. \& GARLAND, C. (1996) What do general practitioners and community mental health teams talk about? Descriptive analysis of liaison meetings in general practice. British Journal of General Practice, 46, 69-71.

MILLARD. D. W. (1996) Maxwell Jones and the therapeutic community. In 150 Years of British Psychiatry (Vol. II) (eds H. Freeman \& G. E. Berrios), pp. 581-604. London: Athlone.

Pullen. I. M. \& Yellowlees, A. (1985) Is communication improving between general practitioners and psychiatrists? British Medical Joumal, 280. 31-33.

WILLIAMS, P. \& WALLACE, B. B. (1974) General practitioners and psychiatrists - do they communicate? British Medical Journal, i, 505-507.

Rebecca J. Tipper, Senior House Officer, Dingleton Hospital, Melrose, Roxburghshire TD6 9HN; *Ian M. Pullen, Consultant Psychiatrist, Dingleton Hospital, Melrose, Roxburghshire TD6 $9 H N$

*Correspondence

\title{
The outcome of rough sleepers with mental health problems admitted to a psychiatric ward
}

\author{
Zoë C. Graham, Frankie S. Salton-Cox and Peter D. White
}

\begin{abstract}
Aims and method To describe the outcome of rough sleepers admitted to an acute psychiatric ward; the professional most involved with the person was interviewed.

Results Eleven out of 12 people admitted with a psychosis were accommodated and in touch with mental health services at follow-up (median of 21 months) compared with two out of 10 people, admitted without a psychosis, accommodated and four out of 10 people in touch with mental health services.

Clinical implications Psychiatric admission with good aftercare is worthwhile for rough sleepers with a psychosis, even if it requires involuntary admission.
\end{abstract}

The plight of rough sleepers has drawn much attention from the media and politicians over the last decade. Those rough sleepers with mental health problems often have particular difficulty in finding appropriate care, especially in the inner city (Scott, 1993; Williams \& Avebury, 1995; Merson, 1996). In the City and East London a specialist health care team has been established with central funding. This team, the East London Homeless Healthcare Team (HHELP) uses people from several disciplines to provide an outreach service, particularly to rough sleepers. Several similar teams have been established nationally (Williams \& Avebury, 1995). Such teams sometimes request mental health assessments with a view to admission. What happens to such patients after admission?

The psychiatric team on Strauss Ward, at St Bartholomew's Hospital, works closely with HHELP and the City of London social services department to provide a comprehensive service. Strauss Ward was opened in 1991 and is the first psychiatric ward to be opened in the City of London for several centuries. Its team provide 
street assessments and in-patient treatment for rough sleepers living literally on their doorstep. When this collaborative model was set up, we were uncertain how useful admission would be, particularly when involuntary. Several of the team believed that admission would be difficult, the psychiatric outcome poor, and people would return to the streets soon after discharge.

Little has been written about the effectiveness of interventions with rough sleepers, although the difficulties of caring for this population are well reported. A high prevalence of severe mental illness and frequent mobility make direct interviewing a time-consuming and unreliable process (Kuhlman, 1994; Marshall, 1994). One exception to this is a study by Merson (1996) of the experiences of another inner London multidisciplinary mental health team which helped the statutory homeless, including rough sleepers. He reported high levels of psychiatric morbidity $(80 \%$ with a psychiatric treatment history) and non-compliance with interventions and follow-up (34\%). Sixty-one per cent of his sample of the homeless showed no improvement, or had uncertain housing, after contact with the team.

No studies have been published for acute generic psychiatric service provision of rough sleepers. This study followed up a consecutive series of rough sleepers who had been admitted to Strauss Ward since it opened. Our definition of 'sleeping rough' was that the person had slept on the streets throughout the night before admission and had no fixed place to live. We particularly studied whether ex-patients were still in touch with services and in accommodation, two of the main challenges faced by those providing services to this group.

\section{The study}

Twenty-two people were identified who had been discharged between 1991 and 1995. Every possible effort was made to ensure that this list was complete. Professionals considered to have the most current and personal knowledge of each person were identified through the care programme approach documents (Department of Health, 1990). This person was then approached and asked to identify the most relevant professional for interview.

The majority (14) of those interviewed were social workers. Three community psychiatric nurses and one primary care nurse were interviewed. In two instances, where no current professional could be traced, a social worker attached to the ward who recalled the person commented on the outcome at last point of contact. For a further two people no professional could be traced who recalled the client in sufficient detail to comment.

The interview of the professional was designed by considering the issues emerging from a literature review (MEDLINE and PsycLIT) and through discussion with staff who had experience of working with rough sleepers (schedule and further data available from the authors). It was divided into three sections. Section one focused on the admission data (age, ethnicity, referral process, physical and mental health problems at admission). Section two described the in-patient care programmes. Section three was concerned with the outcome for each person, as judged by the interviewed professional. This report focuses on the outcome findings.

\section{Findings}

\section{Demographic profile}

Sixteen (73\%) of the people were women and six were men. Their ages at admission ranged from 21 to 66 years (mean age 42 years). Fifteen were UK Caucasian, two were Irish Caucasian, one was UK Afro-Caribbean, two were 'other' Caucasian, and two were unclassified. Sixteen (73\%) of the sample were single, three $(13 \%)$ were married and information for the remainder was not recorded. The median (interquartile range (IQR)) time spent sleeping rough before admission was $3.5(1.2-10)$ years. Patients were followed up for a median (IQR) time of $21(12-28)$ months. The diagnosis as an in-patient and their mental health act status are shown in Table 1. Most of the people had physical illnesses which were treated while in hospital.

Table 1. Mental health profile of in-patients

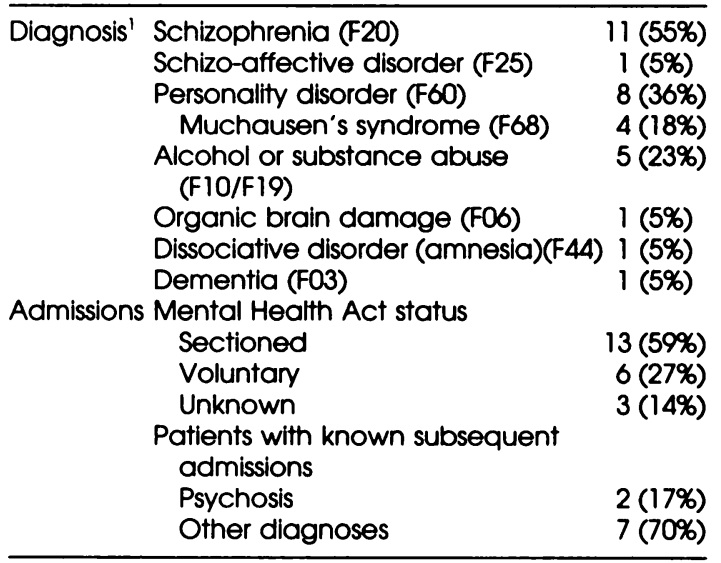

1. Some patients had more than one diagnosis. 
Follow-up contact with psychiatric services and accommodation

Eleven (92\%) of twelve people who had had a psychosis on admission were in touch with generic services at the time of follow-up, compared to four $(40 \%)$ of ten people without a psychosis (Fisher's exact test $P=0.02$ ). Eleven (92\%) of those with a psychosis had confirmed accommodation compared to two (20\%) of those without a psychosis (Fisher's exact test $P=0.002$ ).

\section{Interview with relevant professionals}

Professional carers considered the outcome was 'good' in 11 cases and 'average' in seven cases. The most important factors thought to have ensured a positive outcome were the qualities of the ward staff such as their patience, flexibility and experience with these people $(n=9)$, continuity of care between services $(n=6)$, the admission itself and mental health treatment $(n=6)$ and the cooperative and coordinated approach between the different agencies involved $(n=5)$. Treatment of physical disorders $(n=3)$ and the involvement of a social worker $(n=2)$ were also mentioned.

Several suggestions to improve care were made. The importance of an early intervention and admission were particularly emphasised $(n=6)$. Other suggestions included specialised interventions (e.g. therapy or formal cognitive assessment) $(n=4)$, consideration of alternative discharge plans $(n=4)$ and improvement of communication between staff and agencies $(n=3)$. Two factors which were thought to increase the chances of a negative outcome were the absence of a system to communicate quickly between professionals and services regarding those people with Munchausen's syndrome $(n=5)$ and lack of client motivation $(n=2)$.

\section{Comment}

The most obvious finding of this study was the better outcome for those with a psychosis, compared to those without. This good outcome occurred in spite of a high rate of involuntary admission, and encourages an assertive approach to rough sleepers suffering from a psychosis (Merson, 1996). We did not find the poor social outcome and return to rough sleeping that some of the team feared. The corollary of this was the poor outcome of those without a psychosis. This is less surprising when one considers that four people had Munchausen's syndrome, who comprised an unexpectedly large proportion of those people without a psychosis.

The people in our sample had undergone considerable losses in their lives, which we did not address. Other problems of working with these people included lack of insight and compliance, and an inability to engage in treatment, which necessitated use of the Mental Health Act. Use of a psychologist might enhance engagement of people with and without a psychosis. Psychologists may also have a role in providing complementary interventions (Kuhlman, 1994).

We believed that a good outcome was also related to multi-disciplinary team input and good inter-agency coordination, adequate funding and available move-on accommodation. These all improved the confidence of the ward team that people would be discharged from the ward quickly after treatment, thus avoiding bedblocking, which was an early fear. Planning out-patient care and accommodation as soon as a person was admitted was necessary to avoid long delays in discharge.

\section{Acknowledgements}

We would like to extend our thanks to Jim Drinkwater, Shaun Hare, Caroline Medawar, Percy Aggett and Dr Fiona Starr for their support and advice, as well as the interviewees who participated in the study.

\section{References}

DePaRTMENT OF HeALTH (1990) Caring for People: The Care Programme Approach for People with a Mental Ilness. HMSO: London.

Kuhlman, T. (1994) Psychology on the Streets: Mental Health Practice with Homeless Persons. Chichester: Wiley.

MARSHALL. E. J. (1994) Homelessness and schizophrenia. Schizophrenia Monitor, 4. 1-4.

Merson. S. (1996) A psychiatric service for the homeless mentally ill: the first two years. Psychiatric Bulletin. 20, $662-665$.

SCOTT. J. (1993) Homelessness and mental illness. British Journal of Psychiatry. 162, 314-324.

Williams, R. \& AvebuRY, K. (1995) A Place In Mind: Commissioning and Providing Mental Health Services for People who are Homeless. An NHS Health Advisory Service (HAS) Thematic Review. HMSO: London.

Zoë C. Graham, Clinical Psychologist, Directorate of Child and Adolescent Mental Health. Lewisham \& Guy's Mental Health NHS Trust, 307 Borough High Street, London SE1 1JJ (work completed while on placement at St Bartholomew's Hospital); Frankie S. Salton-Cox. Social Worker with City of London Social Services, Milton Court, Moor Lane, London EC2Y 9BL; and *Peter D. White, Senior Lecturer in Psychological Medicine, St Bartholomew's and the Royal London Medical and Dental School, London EC1A 7BE

*Correspondence 